\title{
Percutaneous Renal Biopsy in the Sitting Position
}

\author{
H. J. GOLDSMITH,* M.D., M.R.C.P. ; J. F. MOORHEAD, †+ M B., CH.B., M.R.C.P. \\ P. J. MOORHEAD, $†$ M.B., CH.B., M.R.C.P.
}

Brit. mcd. F., 1966, 2, 147-148

Percutaneous renal biopsy is now accepted as a useful diagnostic tool, with well-defined indications, risks, and limitations. Most commonly employed is the technique described by Kark and Muehrcke (1954) in which the patient lies prone across a sandbag throughout the procedure, so that the kidney is "fixed" against the posterior parietes and is therefore more easily entered by the biopsy needle.

In a unit dealing with acute renal failure a diagnosis can, on occasion, be established early in the course of the disease only with the help of renal biopsy. We have found that acutely ill patients do not easily tolerate the prone position, but it has usually proved possible to obtain a biopsy with the patient sitting, supported if necessary. This technique was first described by Iversen and Brun (1951), and has been used by R. M. Kark and his associates (personal communication, 1960) in pregnant patients. Its adoption for routine use has not previously been described. A series of 164 consecutive renal biopsies taken in the sitting position is presented.

\section{Methods}

Biopsy is performed in the morning, facilitating observation of the patient during the day. No surgical preparation is required and the patient is encouraged to take his normal breakfast. Except in the case of acute renal failure, biopsy is undertaken only in patients with normal platelet counts and normal bleeding, clotting, and prothrombin times. Normally no premedication is required, cooperation being assured by previous explanation.

The point chosen for biopsy is determined on the $x$-ray film and marked on the patient's skin with a $1 \%$ aqueous solution of gentian violet, as described by Kark and Muehrcke (1964). A kidney close to or overlapping the iliac crest should be avoided, since it may be unduly mobile. Either kidney may be punctured unless there is splenomegaly, when the left side should be avoided.

The patient is seated comfortably on a trolley with his feet resting on a chair seat. The arms are folded across a pillow on his lap, the spine being at right angles to the thighs and the shoulders bowed. Skin and muscle are infiltrated with local anaesthetic to the renal capsule with $5-10 \mathrm{ml}$. of $1 \%$ lignocaine. The depth of the kidney from the skin is determined with an exploring needle and the measurement transferred to the biopsy needle by means of a sterile orange stick. The biopsy needle is now introduced, and, although the respiratory swing may be small when the tip is correctly positioned on the renal capsule, light digital pressure on the cutting needle transmits a characteristic sensation as if it were resting on soft indiarubber. If a satisfactory biopsy is not obtained at the first attempt counter-pressure with the closed fist may be applied by an attendant standing in front of the patient. Pain during biopsy may result from inefficient infiltration or occasionally from trauma to a renal calix.

* Consultant Physician, Regional Urological Centre and Renal Unit, Sefton General Hospital, Liverpool.

† Medical Registrar, Regional Urological Centre and Renal Unit, Sefton General Hospital, Liverpool.

₹ Present address: Renal Division, Georgetown University Hospital, 3800 Reservoir Road, N.W. Washington D.C., U.S.A.
The specimen is drawn carefully from the needle with the tip of an orange stick and immediately placed straight on to a piece of thin cardboard. After air-drying for 30 seconds it is immersed in formol-Zenker solution, or, if washing in two hours is not feasible, in formol-saline solution. This method of mounting before fixation ensures that histological sections through the entire length of the biopsy are easily obtained.

After the biopsy the patient remains recumbent for four hours, and is not permitted to leave the bed for 24 hours, during which time the pulse and blood-pressure are recorded at increasing intervals. A liberal fluid intake is ensured, and this reduces the risk of clot colic. Hypertensive patients are usually given reserpine, $1.5-2.5 \mathrm{mg}$. intravenously, after the biopsy, so that a predictable and safe fall of blood-pressure is procured and the risk of perirenal haematoma-to which such patients are especially liable-is reduced. Biopsy is avoided in patients with untreated malignant hypertension. A mild analgesic is sometimes required to relieve discomfort due to trauma to muscles and fascia.

Sections are routinely stained with haematoxylin and eosin, periodic-acid-Schiff, and Masson's trichrome, additional stains being used when indicated.

\section{Results}

The length of each specimen was measured, and the number of glomeruli, as counted in the best $3-\mu$ section, was recorded. The results are shown in Table $\mathrm{I}$.

\begin{tabular}{|c|c|c|c|c|c|}
\hline $\begin{array}{l}\text { Length of section (mm.). } \\
\text { No. of sections } \ldots\end{array}$ & $\begin{array}{l}. \\
\cdots\end{array}$ & $\begin{array}{c}0-5 \\
20\end{array}$ & $\begin{array}{c}6-10 \\
46\end{array}$ & $\begin{array}{c}11-15 \\
44\end{array}$ & $\begin{array}{c}16+ \\
28\end{array}$ \\
\hline
\end{tabular}

Of 164 consecutive biopsies taken in the sitting position, 26 (16\%) failed to produce diagnostic amounts of renal cortex. In 12 of the 26 , medulla only was found; in five cases liver was obtained; spleen was obtained twice and colon once. In the remainder, muscle, fat, or no tissue was obtained.

In the case of sections containing one to four glomeruli, further sections were always examined, so that more than five glomeruli were usually available for assessment. Out of 138 specimens with glomeruli 116 contained more than 10 per single section (Table II). In medical disorders of the kidney a

TABLE II
\begin{tabular}{l|c|c|c|c|c}
\hline $\begin{array}{l}\text { No. of glomeruli per single section } \\
\text { No. of sections }\end{array}$ & $\begin{array}{c}1-4 \\
. .\end{array}$ & $\begin{array}{c}5-10 \\
17\end{array}$ & $\begin{array}{c}11-20 \\
70\end{array}$ & $\begin{array}{c}20+ \\
46\end{array}$ \\
\hline
\end{tabular}

diagnosis can usually be made when four or more glomeruli are available for examination (Kellow et al., 1959). The success rate obtained by Iversen and Brun (1951), using this method, was $66 \%$. Others using the prone method have had success rates varying from $70 \%$ (Phillipi et al., 1961) to 92\% (Kerr, 1960). 


\section{Discussion}

Our success rate has been at least as good as the average reported with the use of other diverse techniques. However, this would not be sufficient recommendation for widespread adoption of the method, were it not for the additional important advantage of greatly increased comfort, particularly for acutely ill patients. The use of a sandbag, which is necessary with the patient prone, has been avoided, with its accompaniments of discomfort, nausea in susceptible patients, and occasional syncope from obstruction of the venous return.

Patients cooperate well, and the tendency to transfix the kidney with the production of a painful anterior haematoma is minimized. Haemorrhage sufficient to require blood transfusion was not encountered, and surgical intervention has never been called for. The operator's comfort is ensured, since he too is sitting.

Possible disadvantages of the method stem from the fact that the kidney is not held against the diaphragm. Respiration therefore produces little swing in the exploring needle, so that the operator may be less confident of the depth of the kidney. Further, a sclerotic kidney may escape anteriorly at the moment of biopsy. However, these difficulties are in some degree common to all percutaneous techniques.

\section{Summary}

The technique of renal biopsy in the sitting position is described. In a consecutive series of 164 biopsies taken in the sitting position, $138(84 \%)$ satisfactory specimens were obtained.

Grateful acknowledgement is made to Dr. M. McConnell, Consultant Pathologist, and Mr. Alan Scott, Senior Technician, Department of Histology, for the consistently high standard of the histological preparations. We would also like to thank the nursing staff of the Artificial Kidney Unit for skilful assistance.

\section{REFERENCES}

Iversen, P., and Brun, C. (1951). Amer. F. Med., 11, 324. Kark, R. M., and Muehrcke, R. C. (1954). Lancet, 1, 1047. Kellow, W. F., Cotsonas, N. J., Chomet, B., and Zimmerman, H. J. (1959). Arch. intern. Med., 104, 353.

Kerr, D. N. S. (1960). Lancet, 2, 1370 .

Phillipi, P. J., Robinson, R. R., and Langelier, P. R. (1961). Arch. intern. Med., 108, 739 .

\title{
Occupational Infections in the Edinburgh Abattoir
}

\author{
M. E. SCHONELL, * M.B., B.S., M.R.C.P.ED. ; J. G. BROTHERSTON, † F.R.C.v.S., DIP.BACT. \\ R. C. S. BURNETT, $\ddagger$ M.B., CH.B., D.P.H.; J. CAMPBELL, † A.I.M.L.T. ; JOYCE D. COGHLAN,§ B.SC., PH.D. \\ MARGARET A. J. MOFFAT, $\|$ B.SC., PH.D. ; J. NORVAL, M.R.C.V.S. ; J. A. W. SUTHERLAND,** F.I.M.L.T.
}

Brit. med. F., 1966, 2, 148-150

By reason of his occupation the abattoir worker is at particular risk of acquiring one or more of the prevalent zoonoses. In Great Britain these include $Q$ fever, brucellosis, leptospirosis, and louping-ill.

$Q$ fever was first recognized by Derrick (1937) after an outbreak of febrile illness among Brisbane abattoir workers. Since then several outbreaks of $\mathrm{Q}$ fever among abattoir workers have been reported (Irons and Hooper, 1947 ; Shepard, 1947 ; Beech et al., 1962 ; Tonge and Kennedy, 1963). In Great Britain brucellosis is primarily a disease of cattle, and so far only Brucella abortus has been incriminated. Farmers, dairy workers, and veterinary surgeons who come into contact with infected animals or persons who drink unpasteurized milk may become infected (Bothwell, 1963). Brucellosis has also been reported in butchers and slaughtermen (Dalrymple-Champneys, 1960). Leptospirosis is a disease known to occur among several different occupational groups where unhygienic working conditions allow rats and other rodents to proliferate. Cases have been reported in persons employed in the meat trade (Alston and Broom, 1958; Forbes and Wannan, 1964). Louping-ill, a tick-borne meningo-encephalitis, causes serious economic loss of sheep in South-west Scotland, and serological evidence of infection in Glasgow abattoir workers has been reported by Lawson et al. (1949).

* Lecturer, Department of Respiratory Diseases and Tuberculosis, University of Edinburgh.

t Moredun Institute, Edinburgh.

Assistant Medical Officer of Health, City of Edinburgh.

S Lecturer, Department of Bacteriology, University of Edinburgh.

1. Virologist, Wellcome Laboratory, City Hospital, Edinburgh.

Chief Veterinary Inspector to the City of Edinburgh

1. Chief Veterinary Inspector to the City of Edinburg.
Because of the apparent frequency with which the meat worker becomes infected with one of the zoonoses, we decided to assess the incidence of $\mathrm{Q}$ fever, brucellosis, leptospirosis, and louping-ill in Edinburgh abattoir workers. No comprehensive study in abattoir workers appears to have been carried out in this country, and we thought that such a survey might provide information of value to the public health authorities and to practitioners. Evidence of previous infection with one of these diseases was sought by clinical assessment and serological testing.

\section{Materials and Methods}

Blood was taken from 96 men employed at the Edinburgh abattoir: 45 were slaughtermen, including 8 pig slaughtermen, 35 were hide brokers, ${ }^{1} 13$ were gut cleaners, and 3 were employed as clerks.

\section{Clinical Methods}

The men were interviewed in detail, a standard questionary being used. They were questioned about their previous occupations, and in particular were asked whether they had ever been employed in any other occupation which may have predisposed them to infection with one of the zoonoses. The localities in which they had worked were recorded. They were questioned regarding contact with cows, sheep, pigs, and rats, and also whether they had ever drunk unpasteurized milk. A series of clinical questions was used to elicit possible symptoms of a

Hide broker-a man who sorts and grades hides. 